\section{Reducing the Cost of Cancer Care: When Less Is More}

At this year's ASCO meeting, a remarkable event took place. Prominent oncologists from around the world gathered early on Saturday morning to discuss how to reduce the cost of cancer care through a new clinical trial effort that would focus on giving less drug (or alternate cheaper drugs) without compromising outcomes.

I didn't think this up, but I was happy to be part of the discussion. If you let your mind wander, you can come up with a pretty big list of maneuvers based on pharmacokinetics, length of treatment, or substitution of similar but cheaper drugs in a given regimen. After you build that list, though, the task gets a lot harder. What kind of trial is needed to change practice? Equivalency trials are impossibly large and expensive; noninferiority trials are a bit less so, but still pricey. Could we deploy surrogates for outcome? How about a single-arm phase II trial? What, exactly, will it take to convince elite guideline groups, such as NCCN panels, to adopt these changes and incorporate them?

There is not a simple answer. We all recognize the need for really solid evidence to change practice. The gold standard, of course, is a randomized trial. But we also know that trials that lead to registration of a new drug are never based on how little drug can we give. One great example is therapy with monoclonal antibodies. Humanized monoclonal antibodies have an extremely long half-life, and we have no idea about the circulating threshold for efficacy. So these drugs are dosed on a regular schedule without anyone knowing whether enough drug is already on board. And antibodies are really expensive.

Assuming we can design an efficient trial that doctors agree could lead to a change in practice, we have the trivial issue of who will support the trial. I'm guessing the sponsors of the drug would not be interested, but I'd like to be wrong about that. How about the payers? Would CMS or private insurers be willing to foot the bill? Maybe. In the United Kingdom, the National Health Service (NHS) supports the clinical costs, even research costs, of trials that have been vetted through peer review. We could do that here.

This brings up another issue. I have written before about the importance of a publicly funded clinical trial system that answers important questions for which there are no sponsors. We have that in our own cooperative group system, the National Clinical Trials Network (NCTN). So why doesn't the NCTN take this on? To be fair, the charge of the NCTN is to advance and improve care, not make it cheaper. But couldn't that change?

Finally, none of this noble work addresses the elephant in the room. A fundamental driver of healthcare cost is the price of drugs. Concern about drug costs may be the only bipartisan issue left in Congress, so maybe there is a chance that new legislation could be enacted to roll back the price of drugs. I know my colleagues in industry don't like to hear that, but we all have to do our part, right?

The population is aging and more and more people around the globe need cancer care. We must figure out how to make this care more cost-effective or, frankly, rationing of care will begin. And nobody wants that!.

What do you think? Please e-mail correspondence (include contact information) to JNCCN@nccn.org or log into www.editiorialmanager.com/JNCCN to submit a Letter to the Editor.

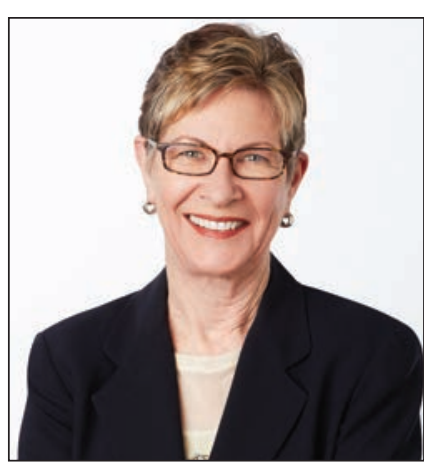

Margaret Tempero, MD

Margaret Tempero, MD, is a Professor of Medicine and Director of the UCSF Pancreas Center and editor-in-chief of JNCCN. Her research career has focused on pancreatic ductal adenocarcinoma, especially in the area of investigational therapeutics. Dr. Tempero has served on the ASCO Board of Directors and as ASCO President. She currently serves on the ASCO Conquer Cancer Foundation Board. She codirected the AACR/ASCO Methods in Clinical Cancer Research and taught this course and similar courses in Europe and Australia. She was founding Chair of the $\mathrm{NCl}$ Clinical Oncology Study Section and served as a member and Chair of the NCl Board of Scientific Counselors Subcommittee A. She is a member of the Scientific Steering Committee and Chair of the Clinical and Translational Study Section for the Cancer Prevention \& Research Institute of Texas. She is or has been on the Scientific Advisory Boards of the Lustgarten Foundation, the Pancreatic Cancer Action Network, the V Foundation, The Alberta Canada Cancer Board, and the EORTC. She served as a member of the Oncology Drug Advisory Committee for the FDA. She has served as Deputy Director and Interim Director for the UNMC Eppley Cancer Center. She is Chief Emeritus of the Division of Medical Oncology at UCSF and served as the founding Deputy Director and Director of Research Programs at the UCSF Helen Diller Family Comprehensive Cancer Center.

doi:10.6004/jnccn.2017.0125

The ideas and viewpoints expressed in this editorial are those of the author and do not necessarily represent any policy, position, or program of NCCN. 